\title{
АКТУАЛИЗАЦИЯ ИЗУЧЕНИЯ АССЕРТИВНОСТИ В РЕШЕНИИ ВОПРОСОВ СОЦИАЛЬНОЙ АДАПТАЦИИ ПОДРОСТКОВ
}

\section{ACTUALIZATION OF THE STUDY OF ASSERTIVENESS IN ADDRESSING ISSUES OF SOCIAL ADAPTATION OF ADOLESCENTS}

\section{J. Shiltsova}

Summary: The article considers assertiveness as a quality of personality that allows you to resist the negative social phenomena of our time and adapt in society. Based on the material studied, the main indicators through which one can study the possession of human assertive behavior are identified. Forms have been developed and a thematic plan for training adolescents in a conscious approach and skills of assertive behavior has been presented. As a result of the work (forming experiment), the main indicators of assertive behavior have undergone significant changes in the direction that contributes to the "correct" social adaptation: teenagers'self-esteem, their self-confidence have grown, anxiety and aggressiveness have decreased. Adolescents have acquired skills in understanding life values, their rights and responsibilities, communication skills, and conflict resolution.

Keywords: self-esteem, opposition to manipulation, values, norms, rights, rules, open behavior, effective adaptation.

\author{
Шильцова Юлия Вячеславовна \\ К.nсх.н., доцент, Рязанский государственный \\ университет имени С.А. Есенина \\ j.shiltsova@gmail.com
}

Аннотация: В статье рассматривается ассертивность как качество личности, позволяющее противостоять негативным социальным явлениям современности и адаптироваться в обществе. На основании изученного материала выделены основные показатели, через которые можно исследовать обладание человеком ассертивным поведением. Разработаны формы и представлен тематический план обучения подростков осознанному подходу и навыкам ассертивного поведения. В результате проведённой работы (формирующего эксперимента) основные показатели ассертивного поведения претерпели значительные изменения в сторону, способствующую «правильной» социальной адаптации: выросла самооценка подростков, их уверенность в себе, снизилась тревожность и агрессивность. Подростки получили навыки понимания жизненных ценностей, своих прав и обязанностей, навыки коммуникации и способов решения конфликтов.

Ключевые слова: самооценка, противостояние манипуляциям, ценности, нормы, права, правила, открытое поведение, эффективная адаптация.

\section{Введение}

$\Pi$ роблема социальной адаптации является в современном социокультурном пространстве одной из ключевых в воспитании подростка. Непрерывные социальные конфликты и их отражение в семье, в образовательных и развивающих структурах, состояние «liquid reality» ( как определяет нестабильность 3. Бауман) [ 1 ] создаёт множество препятствий в овладении детьми элементарными нормами и правилами поведения, в понимании социальных ролей, усвоении необходимых форм деятельности, не подверженности так широко сейчас распространённым манипуляциям - основных факторов, способствующих социальной адаптации личности.

Сформированная ассертивность как способность человека уверенно и с достоинством отстаивать свои права, при этом, не нарушая прав других, может способствовать более эффективной адаптации личности подростка в условиях современного социума. Ассертивность в психологических исследованиях понимается как прямое, открытое поведение, способность отстаивать свои потребности, не направленное на причинение вре- да другим людям, как «интегративная характеристика личности, отражающая её достижения в развитии отношений с другими людьми, дающая возможность эффективно выстраивать своё поведение в зависимости от конкретных условий и в соответствии с принятыми в социуме нормами» $[14, C .3]$.

Ассертивность поведения представляет собой некую «золотую середину» между агрессивностью и пассивностью в поведении человека.

Проблемой исследования, рассматриваемой в настоящей статье является изучение принципов, условий, форм способствующих формированию и развитию ассертивности в условиях образовательного учреждения - средней школы.

Объектом исследования в настоящей статье является ассертивность, как свойство личности подростков. Предметом исследования становятся формы развития ассертивности в воспитании социальной адаптации подростков в образовательно-воспитательном процессе средней школы. 
Современные исследователи, озабоченные создавшейся ситуацией, подчёркивают, что обладание ассертивностью, как социальным свойством личности делает человека сильнее, увереннее в своих убеждениях и соответственно адаптивным к интенсивно меняющимся условиям (Т.В. Антонова, 2004; А.М. Прихожан, 2001; В.Г.Ромек, 1999; Р. Альберти (Alberti, R., 1975); Дж. Вольпе (Wolpe, J., 1958); Р. Васта, М. Хайт и С. Миллер (Vasta, R., Haith, M.M., \& Miller, S.A.,1999); Д. Гелдард и К. Гелдард (Geldard, D. \& Geldard, K., 1999).; С. Риис и Р. Грехам (Rees, S. \& Graham, R.S.,1991); М. Ротерам, М. Армстронг и К. Бураeм (Rotheram, M.J., Armstrong, M., \& Booraem, C.,1982) и др.

При создании и реализации специальной программы обучения подростков ассертивности, дети усваивают знания о себе, о социальных нормах поведения, учатся анализировать образцы и модели требуемого обществом поведения. Как отмечает Е.А. Сорокоумова(2009) [9] при обучении детей нормам и правилам построения отношений происходит одновременное познание ими « образа мира» и « образа своего Я».

В современном обществе становится очевидным, что необходимо профессиональное сопровождение детей в работе по формированию самосознания, способностей понимать себя и другого человека.

Складывающиеся противоречия между необходимостью формирования эффективной адаптивности детей, как интегративного качества юной личности и очевидной неразработанностью ключевых вопросов механизмов развития адаптивности, побуждает к проведению исследований в сфере развития адаптивной личности и поиску оптимальных способов её воспитания.

Из научных исследований можно выделить следующие компоненты ассертивности. На основе анализа работ К. Стьюарта и В. Левиса[7 ] -высокую самооценку личности; на основе исследований Х. Уолкера и и С. Макконнела[7] - уверенность в себе; на основе работ Дж. Вольпе[2 ]- низкую тревожность; из исследований и выводов В. Таннера и У. Холлимана[14]- «конструктивную» ( низкую) агрессивность.

В процессе нашей работы проведён теоретический анализ сущности и содержания ассертивности, охватывающей: когнитивно-смысловые, аффективные и поведенческие компоненты. Формирование ассертивности представляется возможным при условии воздействия на каждую из обозначенных сфер.

Рассмотрим специфику работы с каждой из названных сфер. Поскольку когнитивно-смысловой компонент представляет собой ориентирование и адекватную оценку окружающей действительности, в когнитивной сфере личности возможно формирование убеждений, ассертивных установок и соответственно жизненной позиции. Ведущим показателем когнитивно-смыслового компонента ассертивности является достаточно высокая самооценка.
В эмоциональной сфере представляется возможным формирование открытого выражения своих чувств, мыслей, взглядов «....а также эмоциональная уравновешенность поведения; - ассертивная позиция личности субъекта адаптации, включающая независимость, настойчивость, ответственность, способствует направлению агрессии в конструктивное русло, является развивающей, стимулирующей и плодотворной в решении жизненных ситуаций»[13,С.13 ].

Поведенческий компонент предполагает закрепление ассертивных форм поведения, что находит своё выражение в определённых поведенческих умениях и навыках, моделях поведения, позволяющих приспосабливаться к изменяющимся условиям. «Ассертивное поведение как основа совладающего поведения обеспечивает использование субъектом адаптации внутренних и внешних ресурсов для разрешения сложной ситуации»[13,С.13 ]. Изученный материал и проведённый его анализ позволяет заключить, что для формирования ассертивности требуется разработка стратегий и специальной программы, в которой системно и последовательно внедряются способы, позволяющие развивать ассертивные компоненты и качества.

«Обучение ассертивности удовлетворяет условиям формирования эффективной социальной адаптации. Ассертивность влияет на показатели социальной адаптации ребёнка. ....., ассертивность представляет собой один из психологических механизмов развития социальной адаптации...»[13, С.14 ].

\section{Исследовательская работа}

Исходя из представленных теоретических положений, было начато исследование учащихся в двух классах: дети в возрасте 12-13 лет всего 63 человека. Один из классов был обозначен как контрольный (31 человек), а второй как экспериментальный (32 человека), в котором проводилось специально подготовленным психологом-педагогом поступенчатое обучение навыкам ассертивности. Для эксперимента разработана специальная программа, целью которой стало формирование ассертивности как развития её ведущих компонентов: высокой самооценки, уверенности в себе, снижения тревожности, конструктивной ( низкой) агрессивности и умений «правильной коммуникации». В комплексе с обозначенными компонентами следует развитие конструктивных навыков общения, организация на принципах гуманистической психологии взаимодействия между подростками и взрослыми. Основными руководящими принципами гуманистической педагогики в проводимой работе являлись: принятие других такими, какие они есть; стремление к взаимопониманию, к пониманию интересов других людей; создание безопасности и поддержки.

Психолог-педагог в лекционной и практической 
формах представляла детям инструменты - психологические средства, обеспечивающие их личностное развитие: понимание самих себя, своих потребностей; понимание других людей; закономерности общения. Психологические средства представлены в формах теоретических занятий (лекции), практических (тренинги) и деловой игры.

Курс экспериментального обучения был рассчитан на 18 часов дополнительных занятий в первой и второй четвертях 2019 года: 6 часов лекционных занятий, 11тренинги, 1-«деловая игра».

Таблица1.

Тематический план

\begin{tabular}{|c|c|c|c|}
\hline & Лекции & Тренинги & Задания для самостоятельной работы \\
\hline 1. & $\begin{array}{l}\text { Ассертивность - качество человеческой } \\
\text { личности; духовно-нравственная категория }\end{array}$ & & \\
\hline 2. & & Обучение навыкам ассертивного поведения & $\begin{array}{l}\text { Припомнить или придумать жизненные ситуации, } \\
\text { в которых необходимо проявить навыки ассертив- } \\
\text { ного поведени }\end{array}$ \\
\hline 3. & $\begin{array}{c}\text { Социальные ценности в современной жизни; по- } \\
\text { нимание смысла собственной жизни; } \\
\text { социальная безопасность. }\end{array}$ & & $\begin{array}{c}\text { Рассмотреть особенности личностных ценностей } \\
\text { человека }\end{array}$ \\
\hline 4. & & Закрепление навыков ассертиного поведения & $\begin{array}{c}\text { Работа с ситуациями, где необходимы навыки } \\
\text { ассертивного поведения }\end{array}$ \\
\hline 5. & Самооценка; самоактуализирующаяся личность & & $\begin{array}{c}\text { Рассмотрение ситуаций с проявлением } \\
\text { моральных принципов и прав ассертивного } \\
\text { человека. }\end{array}$ \\
\hline 6 & & Закрепление навыков ассертиного поведения & $\begin{array}{l}\text { Рассмотрение ситуаций с проявлением самоактуа- } \\
\text { лизации личности } \\
\end{array}$ \\
\hline 7 & $\begin{array}{l}\text { Взаимоотношения подростков и взрослых. } \\
\text { Подключение родителей к обучению навыкам } \\
\text { ассертивного поведения. }\end{array}$ & & $\begin{array}{l}\text { Рассмотрение ситуаций с проявлением взаимоот- } \\
\text { ношений взрослых и подростков }\end{array}$ \\
\hline 8. & & Закрепление навыков ассертиного поведения & $\begin{array}{c}\text { Рассмотрение ситуаций с проявлением } \\
\text { качеств взаимопонимания, милосердия, } \\
\text { взаимопомощи }\end{array}$ \\
\hline 9. & $\begin{array}{c}\text { Взаимоотношения в коллективе сверстников: пре- } \\
\text { одоление агрессии. }\end{array}$ & & $\begin{array}{c}\text { Рассмотрение ситуаций с проявлением } \\
\text { взаимоотношений в коллективе сверстников }\end{array}$ \\
\hline \multicolumn{4}{|c|}{ Этап промежуточного контроля } \\
\hline 10 & & Закрепление навыков ассертиного поведения & $\begin{array}{c}\text { Рассмотрение ситуаций с проявлением ситуации } \\
\text { преодоления агрессивного поведения }\end{array}$ \\
\hline 11. & & Закрепление навыков ассертиного поведения & $\begin{array}{c}\text { Описать качества ассертивного человека и охарак- } \\
\text { теризовать значимость этих качеств }\end{array}$ \\
\hline 12. & & Закрепление навыков ассертиного поведения & $\begin{array}{l}\text { Охарактеризовать ответственность как необходи- } \\
\text { мое качество личности }\end{array}$ \\
\hline 13. & & Закрепление навыков ассертиного поведения & $\begin{array}{c}\text { Охарактеризовать внешние проявления ассертив- } \\
\text { ного человека }\end{array}$ \\
\hline 14 & & Закрепление навыков ассертиного поведения & $\begin{array}{c}\text { Охарактеризовать атмосферу, которую } \\
\text { ассертивный человек может создавать в кругу } \\
\text { своих сверстников }\end{array}$ \\
\hline 15 & & Закрепление навыков ассертиного поведения & $\begin{array}{c}\text { Может ли ассертивный человек изменить свою } \\
\text { точку зрения под влиянием аргументов? }\end{array}$ \\
\hline 16. & & Закрепление навыков ассертиного поведения & $\begin{array}{c}\text { Как защитить себя от нечестных и корыстных } \\
\text { мнипуляций? }\end{array}$ \\
\hline 17 & & Закрепление навыков ассертиного поведения & $\begin{array}{l}\text { 0характеризовать основные функции ассертивного } \\
\text { поведения личности. Что представляет собой со- } \\
\text { циальная зрелость личности? }\end{array}$ \\
\hline 18 & & $\begin{array}{c}\text { Деловая игра: противостояние позициям } \\
\text { манипуляторов. }\end{array}$ & \\
\hline
\end{tabular}


Согласно представленного плана, работа по формированию навыков ассертивного поведения началась со второй недели сентября 2019 года по согласованию с администрацией школы, коллективом педагогов и родителями.

По завершении первого полугодия бы проведён диагностический этап, который позволил выявить результаты эксперимента. Изучение изменений в поведении учащихся проводилось на основании следующих показателей: развития самооценки; развития уверенности в себе; снижения тревожности; снижения агрессивности.

Изучение самооценки проводилось на основании теста по методике (опроснике) Р.В. Овчаровой [5]. Перед началом практической работы были продиагностированы все учащиеся двух классов.

Таблица 2

Показатели самооценки в \% в начале констатирующего эксперимента

\begin{tabular}{|c|c|c|c|}
\multirow{2}{*}{ классы } & \multicolumn{3}{|c|}{ Уровни самооценки } \\
\cline { 2 - 4 } & Высокий & Средний & Низкий \\
\hline экспериментальный & 10 & 63 & 27 \\
\hline контрольный & 13 & 69 & 18 \\
\hline
\end{tabular}

На этапе промежуточного контроля показатели самооценки в \%

\begin{tabular}{|c|c|c|c|}
\multirow{2}{*}{ классы } & \multicolumn{3}{|c|}{ Уровни самооценки } \\
\cline { 2 - 4 } & Высокий & Средний & Низкий \\
\hline экспериментальный & 30 & 45 & 25 \\
\hline контрольный & 14 & 69 & 17 \\
\hline
\end{tabular}

Уровни самооценки в экспериментальном классе поднимались достаточно медленно до высокой и средней. На завершающем этапе формирующего эксперимента появились достаточно выпуклые результаты работы с учащимися.

Таблица 3.

Показатели самооценки в \%

\begin{tabular}{|c|c|c|c|}
\multirow{2}{*}{ классы } & \multicolumn{3}{|c|}{ Уровни самооценки } \\
\cline { 2 - 4 } & Высокий & Средний & Низкий \\
\hline экспериментальный & 60 & 35 & 5 \\
\hline контрольный & 17 & 70 & 13 \\
\hline
\end{tabular}

Уровни самооценки в экспериментальном классе до высокого и среднего значительно поднялись. По методике В.Г. Ромека [8]определены показатели уровней уверенности в себе.

Показатели уверенности в себе в \% в начале констатирующего эксперимента.

\begin{tabular}{|c|c|c|c|}
\multirow{2}{*}{ классы } & \multicolumn{3}{|c|}{ Уровни самооценки } \\
\cline { 2 - 4 } & Высокий & Средний & Низкий \\
\hline экспериментальный & 12 & 60 & 28 \\
\hline контрольный & 15 & 69 & 16 \\
\hline
\end{tabular}

На этапе промежуточного контроля показатели уверенности в себе в \%

\begin{tabular}{|c|c|c|c|}
\multirow{2}{*}{ классы } & \multicolumn{3}{|c|}{ Уровни самооценки } \\
\cline { 2 - 4 } & Высокий & Средний & Низкий \\
\hline экспериментальный & 39 & 36 & 25 \\
\hline контрольный & 15 & 69 & 16 \\
\hline
\end{tabular}

Уровни самооценки в экспериментальном классе поднимались достаточно медленно до высокой и средней.

На завершающем этапе формирующего эксперимента появились достаточно высокие результаты работы с учащимися.

Показатели уверенности в себе в \%

\begin{tabular}{|c|c|c|c|}
\multirow{2}{*}{ классы } & \multicolumn{3}{|c|}{ Уровни самооценки } \\
\cline { 2 - 4 } & Высокий & Средний & Низкий \\
\hline экспериментальный & 63 & 33 & 4 \\
\hline контрольный & 17 & 70 & 13 \\
\hline
\end{tabular}

Уровни уверенности в себе в экспериментальном классе до высокого и среднего значительно поднялись. В контрольный группе отмечены совсем незначительные изменения, которые можно объяснить влиянием образовательного процесса на повышение самосознания подростков и соответственно повышения их самооценки и уверенности в себе.

Далее исследованы уровни тревожности по методике Ч.Д.Спилбергера [10].

Таблица 4.

Показатели уровня тревожности в \% в начале констатирующего эксперимента

\begin{tabular}{|c|c|c|c|}
\multirow{2}{*}{ классы } & \multicolumn{3}{|c|}{ Уровни самооценки } \\
\cline { 2 - 4 } & Высокий & Средний & Низкий \\
\hline экспериментальный & 10 & 50 & 40 \\
\hline контрольный & 12 & 50 & 38 \\
\hline
\end{tabular}

На этапе промежуточного контроля показатели уровня тревожности в \%

\begin{tabular}{|c|c|c|c|}
\multirow{2}{*}{ классы } & \multicolumn{3}{|c|}{ Уровни самооценки } \\
\cline { 2 - 4 } & Высокий & Средний & Низкий \\
\hline экспериментальный & 7 & 43 & 50 \\
\hline контрольный & 12 & 47 & 41 \\
\hline
\end{tabular}

На завершающем этапе формирующего эксперимента появились достаточно высокие результаты работы с учащимися.

Показатели тревожности в \%

\begin{tabular}{|c|c|c|c|}
\multirow{2}{*}{ классы } & \multicolumn{3}{|c|}{ Уровни самооценки } \\
\cline { 2 - 4 } & Высокий & Средний & Низкий \\
\hline экспериментальный & 3 & 17 & 80 \\
\hline контрольный & 12 & 47 & 41 \\
\hline
\end{tabular}


В результате работы в экспериментальной группе замечено значительное снижение уровня тревожности. Показатели тревожности в контрольной группе остались прежние.

В исследовании такого показателя как агрессивность нами были использованы методики опросника «Агрессивность» А.И. Крупнова [4], опросник «Самооценка форм агрессивного поведения (модифицированный вариант А.Басса-Дарки)».

Таблица 5.

Показатели уровня агрессивности в \% в начале констатирующего эксперимента

\begin{tabular}{|c|c|c|c|}
\multirow{2}{*}{ классы } & \multicolumn{3}{|c|}{ Уровни самооценки } \\
\cline { 2 - 4 } & Высокий & Средний & Низкий \\
\hline экспериментальный & 15 & 47 & 38 \\
\hline контрольный & 18 & 50 & 32 \\
\hline
\end{tabular}

На этапе промежуточного контроля показатели уровня агрессивности в \%

\begin{tabular}{|c|c|c|c|}
\multirow{2}{*}{ классы } & \multicolumn{3}{|c|}{ Уровни самооценки } \\
\cline { 2 - 4 } & Высокий & Средний & Низкий \\
\hline экспериментальный & 10 & 55 & 35 \\
\hline контрольный & 12 & 56 & 32 \\
\hline
\end{tabular}

На завершающем этапе формирующего эксперимента появились достаточно высокие результаты работы с учащимися.

\begin{tabular}{|l|c|c|c|}
\multicolumn{4}{|c|}{ Показатели агрессивности в \% } \\
\cline { 2 - 4 } классы & Высокий & Средний & Низкий \\
\hline экспериментальный & 5 & 20 & 75 \\
\hline контрольный & 12 & 38 & 50 \\
\hline
\end{tabular}

\section{Зак^ючение}

В настоящей статье рассматриваются результаты проведённого эксперимента по формированию ассертивного поведения подростков 12-13 лет. Представлены основные составляющие ассертивного поведения подростков, через исследование которых видится возможным выявить результаты работы согласно представленного в статье тематического плана теоретических и практических занятий, позволяющих объяснить многие вопросы проблематики социальной адаптации в современных условиях. Перед началом эксперимента были изучены теоретические и практические материалы по проблематике ассертивности, был разработан тематический план и материалы работы с учащимися (тексты, ситуации для анализа, вопросы). На основных этапах эксперимента были отмечены показатели уровня самооценки, уверенности в себе, снижения тревожности и снижения уровня агрессивности до конструктивной (т.е. необходимой).
Во время чтения лекций и проведения практических занятий был отмечен значительный интерес учащихся к решению проблемных ситуаций, связанных с социальной адаптацией, отмечено желание учащихся принимать участие в психологических играх, стремления к пониманию многих сложных вопросов, старания измениться в лучшую сторону. Кроме тестовых обследований, были использованы методы наблюдения, констатации отдельных замеченных изменений, бесед с участниками эксперимента, их родителями и учителями-предметниками - это послужило дополнительным материалом для выводов:

- ассертивность, как качество личности, способность убедительно отстаивать свои права без ущемления прав других, как способность открыто выражать своё мнение, как позитивная открытость и настойчивость представляет собой сложное образование, содержащее следующие компоненты; когнитивно-смысловой, аффективный и поведенческий. Самооценка представляет собой ключевой параметр ассертивности в поведении личности. Уверенность в себе и низкая (нормальная) тревожность является ключевым компонентом аффективного компонента. Конструктивная ( низкая, необходимая) агрессивность представляет собой ключевой звено поведенческого компонента;

- направленная на формирование в экспериментальной группе обозначенных компонентов ассертивности программа, как показывают данные на констатирующем и формирующем этапах эксперимента, представляется достаточно эффективной, поскольку разработанные и проведённые занятия с подростками выпукло представляют результаты формирующейся ассертивности;

- проведённые согласно программы теоретические и практические занятия с подростками способствовали развитию таких компонентов ассертивности, как достаточно высокий уровень самооценки и уверенности в себе, снижение уровней тревожности и агрессивности;

- уровень самооценки позитивно коррелирует с уровнем уверенности в себе и отрицательно коррелирует с снижением тревожности и агрессивности;

Таким образом, проведённое исследование показало, что умения решать вопросы коммуникации и взаимодействия с окружающим миром - ассертивное поведение подростков позволяет существенно повысить их социальную адаптацию. Участвовавшие в эксперименте подростки высказали своё желание и далее получать навыки социальной адаптации в дополнительном образовании в школе. 


\section{ЛИТЕРАТУРА}

1. Бауман, 3. Текучая современность / пер. с англ. под ред. Ю.В. Асочакова. СПб.: Питер, 2008.240с.

2. Вольпе, Дж. На пути к созданию научной психотерапии // Эволюция психотерапии / Дж. Вольпе. -1998. Т.2. Москва: НФ «Класс». - 272с.

3. Каппони, В. Новак, Т. Сам себе психолог / В. Каппони, Т. Новак. - СПб. Питер. 2001. - 224 с.

4. Крупнова, А.И. Сборник научных статей, посвященный 70-летию А.И. Крупнова. - М.: РУДН, 2009. - 269-277 С.

5. Овчарова, Р. В. Психологическое сопровождение родительства / Р.В. Овчарова. - М., Институт психотерапии. - 2003. - 319 с.

6. Реан, А. А. Психология адаптации личности. Анализ. Теория. Прак тика / А.А. Реан. СПб.: прайм-ЕВРОЗНАК, 2006. - 479 с.

7. Роджерс, К. Консультирование и психотерапия / К. Роджерс. Перевод с англ. / К. Роджерс. - М., 2005. - 98 с.

8. Ромек, В.Г. Понятие уверенности в себе в современной социальной психологии / В.Г. Ромек // Психологический вестник Ростовского государственного университета, Выпуск 1, Часть 2. Изд-во РГУ, 1996. - С.132-146.

9. Сорокоумова, Е.А. Возрастная психология: краткий курс / Е.А. Сорокоумова. - Изд.: Питер. 2009. - 208 с.

10. Ханин, Ю. Л. Краткое руководство к шкале реактивной и личностной тревожности Ч. Д. Спилбергера / Ю.Л. Ханин - Л., 1976.- 18 с.

11. Харламенкова, Н. Е. Самоутверждение подростка / Н.Е. Харламенкова. - М. : ИП РАН, 2007. - 384 с.

12. Шильцова, Ю.В. Ассертивность как механизм социальной адаптации дошкольников/ Ю.В. Шильцова. Научное издание. LAP, Lambert Academic Publishing GmbH\&Co.KG. Saarbruken, 2012. -172 c.

13. Шильцова, Ю.В. Ассертивность как один из психологических механизмов развития социальной адаптации у детей старшего дошкольного возраста. Автореферат канд. дисс. психол. наук/ Ю.В. Шильцова. -М. 2012. -22с.

14. Alberti, R. \& Emmons, M. (1982). Your perfect right: A guide for assertive living. California: Impact, San Luis Obispo. -178 p.

(с) Шильцова Юлия Вячеславовна (j.shiltsova@gmail.com).

Журнал «Современная наука: актуальные проблемы теории и практики»

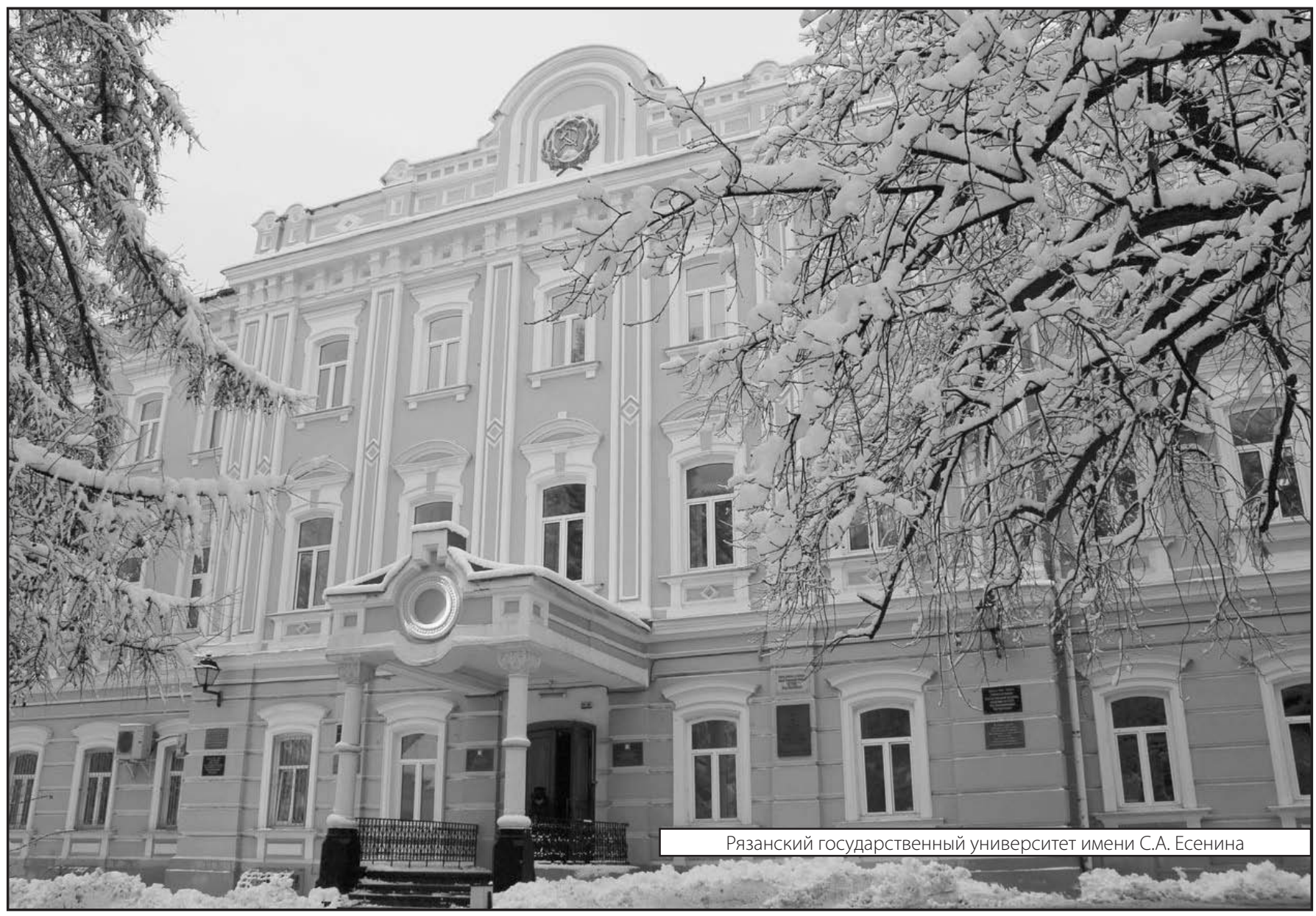

